\title{
Multi-Foulant-Resistant Material Design by Matching Coating-Fluid Optical Properties
}

\author{
Cigdem Toparli, ${ }^{\dagger}$ Max Carlson, ${ }^{\dagger}$ Minh A. Dinh, ${ }^{\dagger}$ Bilge Yildiz, ${ }^{\dagger}, \ddagger$ and Michael P. \\ Short ${ }^{*, \dagger}$ \\ $\dagger$ Department of Nuclear Science and Engineering, Massachusetts Institute of Technology, \\ Cambridge, MA, 02139, USA \\ $\ddagger$ Department of Materials Science and Engineering, Massachusetts Institute of Technology, \\ Cambridge, MA, 02139, USA \\ E-mail: hereiam@mit.edu \\ Phone: +1-617-347-7763
}

\section{Supporting Information Available}

Fig. 1 shows survey XPS spectra of all coatings studied, confirming the presence of elements applied from the sputtering targets. Most notable is that fluorine was not seen in the amorphous FTO specimen, though the combination of initial $2 \%$ doping and likely evaporation or outgassing during PVD is likely responsible for lowering the actual fluorine concentration in the as-deposited FTO films. Fig. 3 shows FIB cross sectional images of the coatings used in this study. This thickness information was fed directly into the while light reflectometry model fits, to obtain more accurate and unique fits for refractive index and absorption (n \& k) values. 

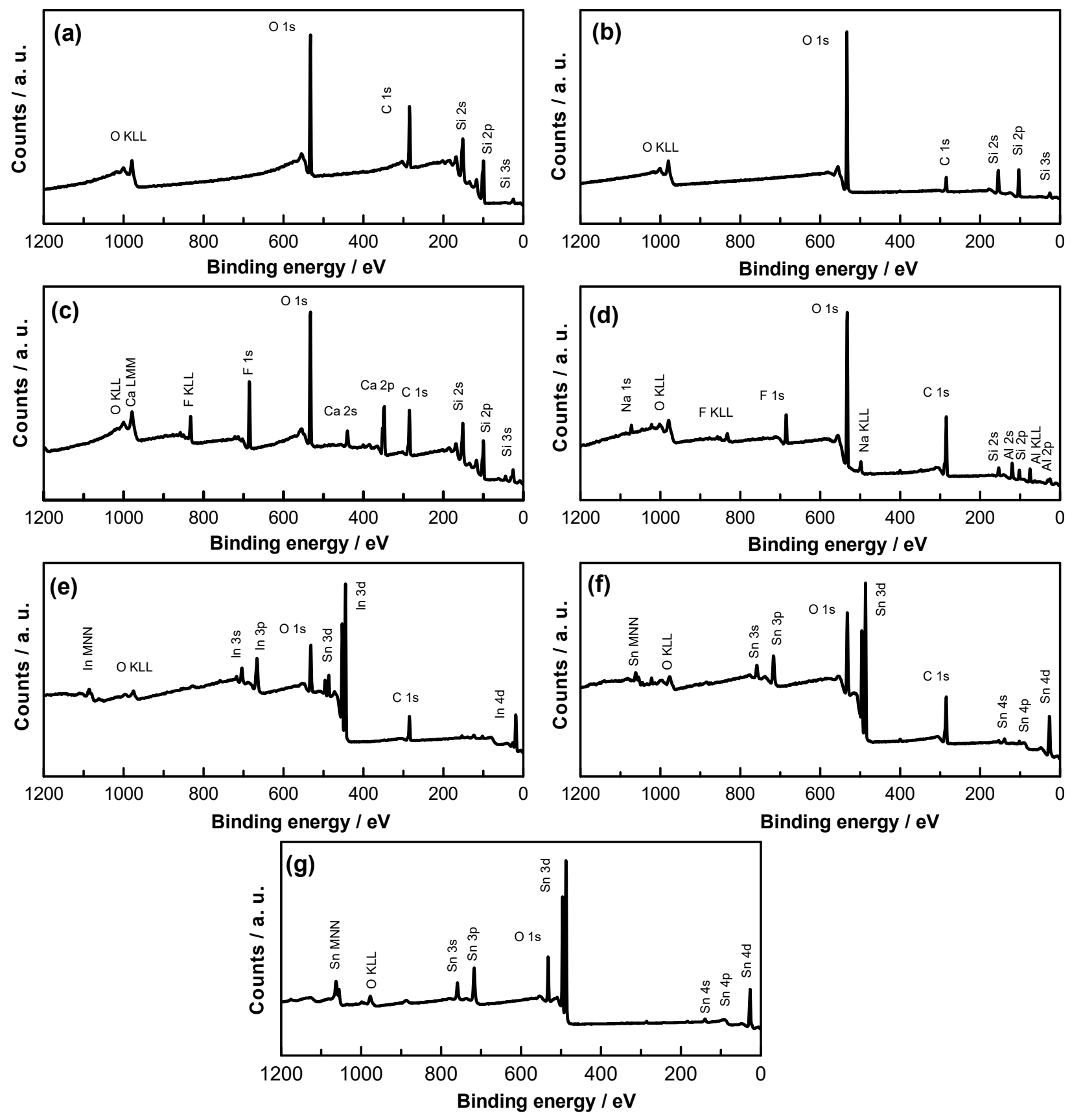

Figure 1: XPS survey spectra of potentially foulant-agnostic coatings. (a) Si substrate (b) $\mathrm{SiO}_{2}$ (c) $\mathrm{CaF}_{2}$ (d) $\mathrm{Na}_{3} \mathrm{AlF}_{6}$ (e) ITO (f) amorphous FTO (g) crystalline FTO 

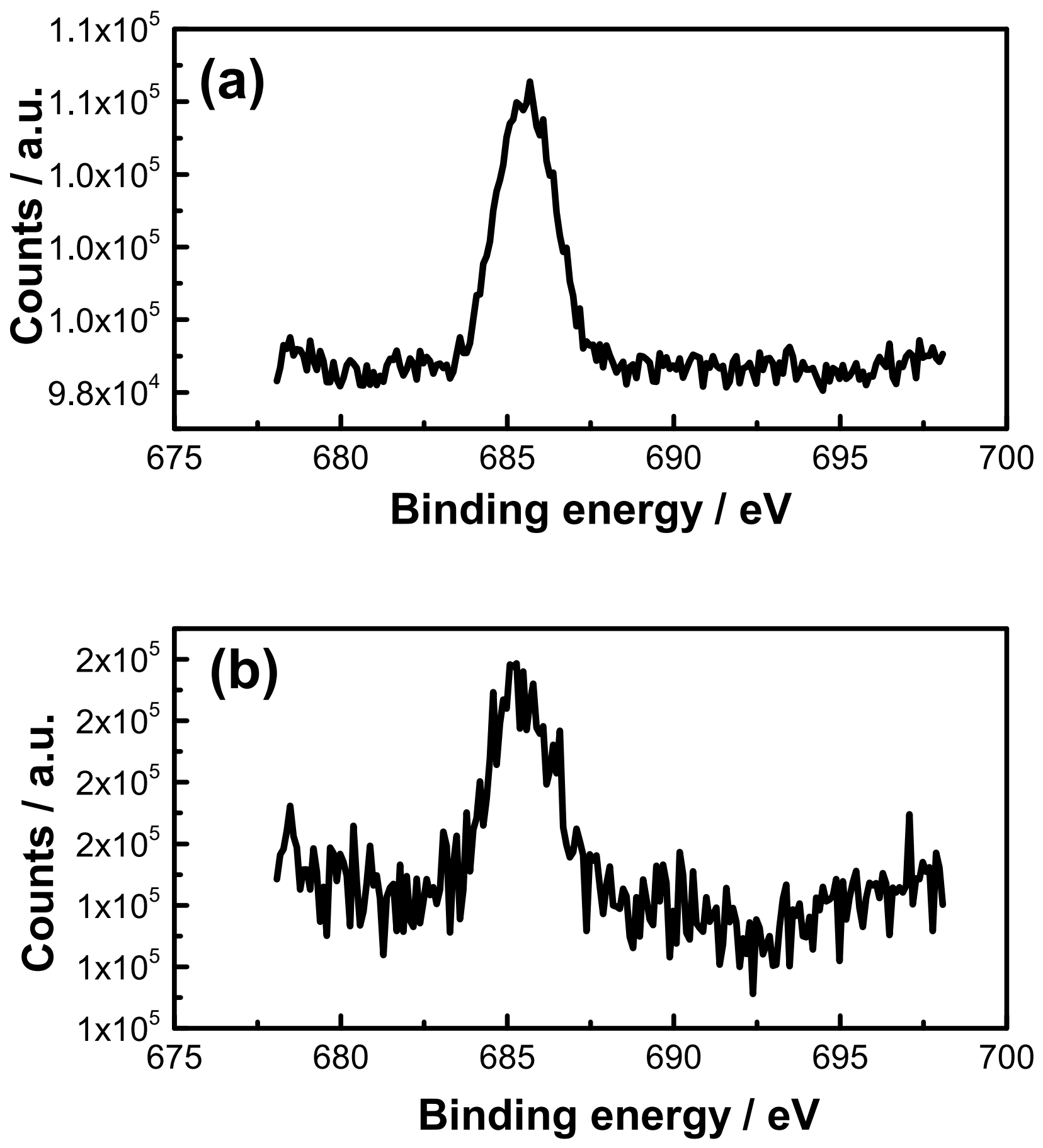

Figure 2: High resolution scan of F peak (a) amorphous FTO (b) crystalline FTO 

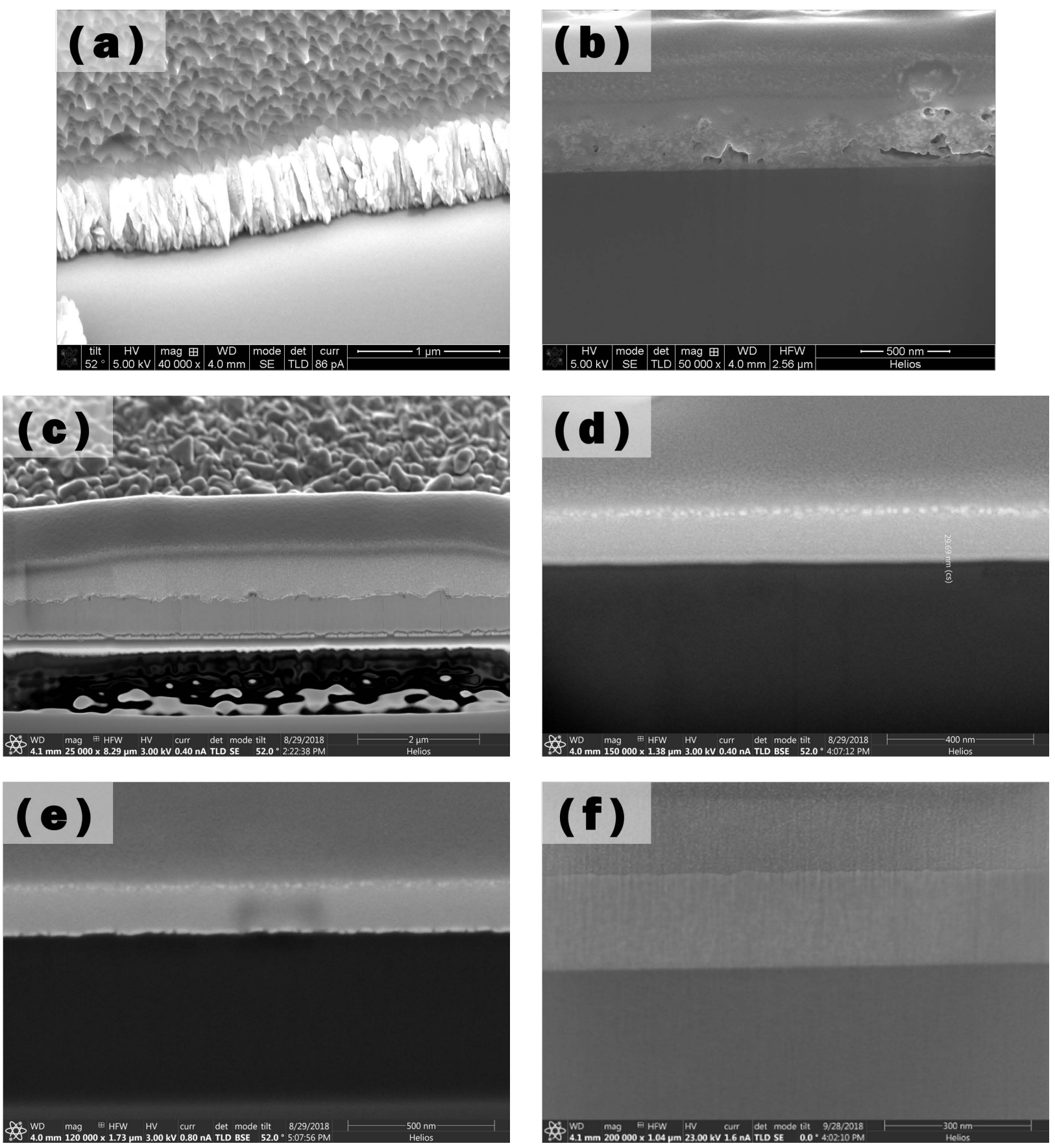

Figure 3: Cross section images of the coatings obtained by FIB analysis. (a) $\mathrm{CaF}_{2}$ (b) $\mathrm{Na}_{3} \mathrm{AlF}_{6}$ (c) amorphous FTO (d) ITO (e) $\mathrm{SiO}_{2}$ (f) crystalline FTO 

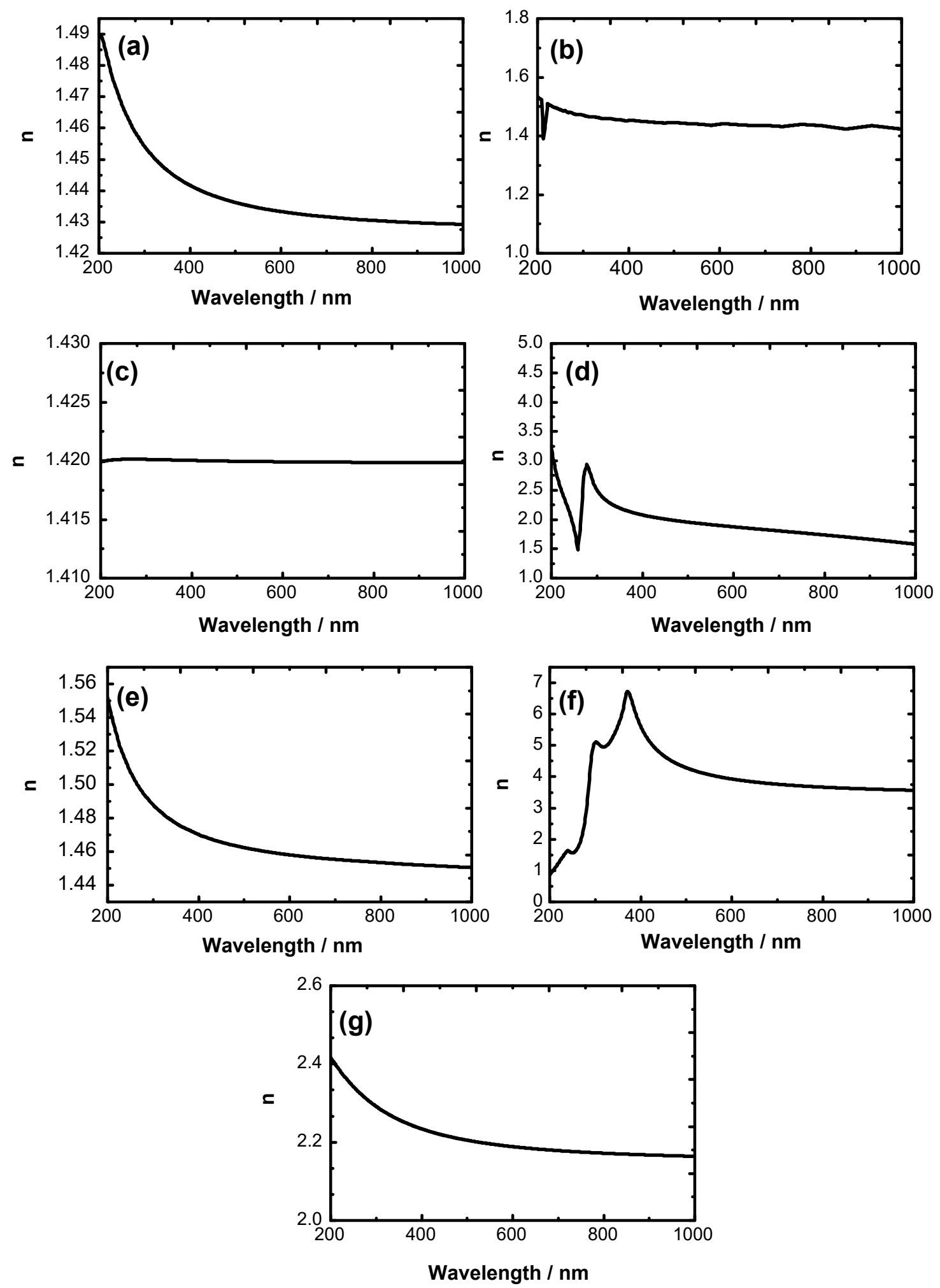

Figure 4: Full spectral optical constants deduced from white light interferometry. The thicknesses obtained from FIB cross sectional analysis were used as input parameters. (a) $\mathrm{CaF}_{2}$ (b) $\mathrm{Na}_{3} \mathrm{AlF}_{6}$ (c) amorphous FTO (d) ITO (e) $\mathrm{SiO}_{2}$ (f) $\mathrm{Si}$ (g) Crystalline FTO 